\title{
Improving the corrosion resistance of steels intended for use in seawater
}

\author{
Irina Rodionova $^{1, *}$, and AndreyAmezhnov ${ }^{1}$ \\ ${ }^{1}$ State Scientific Center Federal State Unitary Enterprise I. P. Bardin Central Research Institute for Ferrous Metallurgy, 105005 \\ Moscow, 23/9 Radio Street, Building 2, Moscow, Russia
}

\begin{abstract}
The results of study of influence of the chemical composition of steel, the structural condition and contamination of nonmetallic inclusions of various types on its corrosion resistance in seawater are presented in the paper. The requirements for increased-corrosion-resistance steel for marine conditions and oilfield pipelines have been compared. It has been shown that a mandatory requirement for ensuring high corrosion resistance of steels is to ensure the purity of steels from unfavorable types of nonmetallic inclusions. It has also been shown that reducing the carbon content and alloying with nickel lead to an increase in the corrosion resistance of steel.
\end{abstract}

\section{Introduction}

Improving the resistance of steel metal products against general and local corrosion in neutral aqueous media with a $\mathrm{pH}$ value of $\mathrm{pH} 6-8$ is important for numerous structures operating in atmospheric conditions, in seawater, for heat pipelines, infield pipelines, water supply systems, and many other types of structures and equipment.

Systematic studies on improving the reliability service of steels for oilfield pipelines have shown the possibility of significantly (by $2-5$ times) increasing their corrosion resistance by optimizing the chemical composition, structural condition, and increasing the purity of steel from certain types of nonmetallic inclusions [1]

The influence of nonmetallic inclusions (NMI) on the corrosion resistance of steels for oilfield pipelines has been dealt with in many papers [1-3]. Papers [2-3] consider the evolution of the composition of NMIs at different stages of development of metallurgical technologies, the influence of the composition of NMIs on their corrosiveness and, accordingly, on the corrosion resistance of steel. It has been noted that magnesiumaluminate-based NMIs in modern steels have a complex composition; the oxide component of such inclusions may contain calcium, magnesium, aluminum, and some other elements in different proportions. The corrosiveness of NMIs and, accordingly, corrosion resistance of steels depend on the ratios of the content of such elements. In the production of increased-corrosionresistance steels for oilfield pipelines, it is advisable to provide technological methods aimed at the formation of nonmetallic inclusions of favorable morphology.

The influence of chemical composition and structural characteristics on the corrosion resistance of steels for oilfield pipelines was considered in [4]. It was noted that in order to ensure high corrosion resistance of K52-K56 strength class steels under operating conditions of oilfield pipelines, it was advisable to alloy the steel with chrome and copper and limit the aluminum content to no more than $0.01-0.02 \%$. At the same time, the carbon content in the range of $0.035-0.115 \%$ did not have a significant effect on the corrosion resistance of steel. Papers [4-5] made it clear that the formation of numerous nanosized (especially with sizes less than 3 $\mathrm{nm}$ ) precipitates of excess phases of the interphasic type, niobium carbide, and even more so, vanadium carbide, obvious in steels with increased vanadium content (at the level of $0.1 \%$ ), leads to a decrease in corrosion resistance.

It should be noted that oilfield pipelines, in contrast to the main pipelines, transport, in addition to oil, highly mineralized water, which is pumped into the oil reservoir to enhance oil recovery. Similar conditions, namely the contact of steel products with aqueous media containing chlorine ions, are characteristic of parts and structures used in seawater. Therefore, approaches to improving the corrosion resistance of steels for oilfield pipelines can be used in work aimed at improving the corrosion resistance of steels operating in marine conditions, in particular, shipbuilding steels.

The purpose of this work was to determine the nature of influence of the chemical composition of steel, structural condition, and contamination with nonmetallic inclusions of various types on its corrosion resistance in seawater and to compare the requirements for increasedcorrosion-resistance steel for marine conditions and oilfield pipelines.

\section{Experimental part}

Studies of the influence of chemical composition and structural condition on corrosion resistance were carried

\footnotetext{
* Corresponding author: igrodi@mail.ru
} 
out on samples of hot-rolled steel of laboratory smelting described in [4-5]. The chemical composition of the investigated steels is shown in Table 1.

Table 1. The chemical composition of chromium steels, wt. \%

\begin{tabular}{|c|c|c|c|c|c|c|c|}
\hline \multirow{2}{*}{$\begin{array}{c}\text { Smelt } \\
\text { No. }\end{array}$} & \multicolumn{8}{|c|}{ Content of elements, \% wt. } \\
\hline 1 & 0.115 & 0.037 & 0.53 & 0.002 & 0.004 & 0.76 & 0.50 \\
\hline 2 & 0.059 & 0.21 & 0.60 & 0.002 & 0.004 & 0.80 & 0.50 \\
\hline 3 & 0.099 & 0.26 & 0.60 & 0.002 & 0.004 & 0.41 & 0.49 \\
\hline 4 & 0.059 & 0.27 & 0.57 & 0.002 & 0.004 & 0.40 & 0.50 \\
\hline 5 & 0.079 & 0.19 & 0.92 & 0.002 & 0.004 & 0.84 & 0.18 \\
\hline 6 & 0.035 & 0.25 & 0.59 & 0.002 & 0.004 & 0.79 & 0.097 \\
\hline 7 & 0.078 & 0.23 & 0.57 & 0.002 & 0.004 & 0.40 & 0.096 \\
\hline 8 & 0.038 & 0.28 & 0.58 & 0.002 & 0.004 & 0.42 & 0.097 \\
\hline Smelt & \multicolumn{8}{|c|}{ Content of elements, \% wt. } & \\
\cline { 2 - 9 } No. & $\mathbf{C u}$ & $\mathbf{A l}$ & $\mathbf{T i}$ & $\mathbf{V}$ & $\mathbf{N b}$ & $\mathbf{N}$ & Fe \\
\hline 1 & 0.50 & 0.005 & 0.019 & 0.070 & 0.031 & 0.0081 & Base \\
\hline 2 & 0.11 & 0.006 & 0.016 & 0.072 & 0.056 & 0.0100 & Base \\
\hline 3 & 0.12 & 0.028 & 0.043 & 0.068 & 0.048 & 0.0080 & Base \\
\hline 4 & 0.48 & 0.024 & 0.032 & 0.074 & 0.056 & 0.0076 & Base \\
\hline 5 & 0.11 & 0.020 & 0.016 & 0.065 & 0.048 & 0.0072 & Base \\
\hline 6 & 0.51 & 0.018 & 0.017 & 0.068 & 0.049 & 0.0077 & Base \\
\hline 7 & 0.51 & 0.019 & 0.017 & 0.069 & 0.050 & 0.0082 & Base \\
\hline 8 & 0.12 & 0.012 & 0.015 & 0.070 & 0.051 & 0.0075 & Base \\
\hline
\end{tabular}

The results of studies of the structure, mechanical properties, as well as the corrosion resistance of steels of all variants, with respect to the operating conditions of oilfield pipelines, are also shown in paper [4]. In this paper, the corrosion resistance of steels was evaluated according to the Method for Determining the Corrosion Resistance of Carbon and Low-Alloy Steels and Related Products by Measuring the Saturation Current Density of the Anodic Dissolution of Steel in a Corrosive Environment by the Electrochemical Method (the serial number and registration code in the Federal Register of Measurement Methods Used in Distribution of State Metrological Control and Supervision) FR.1.31.2015.19527 [6]. The method below is conventionally called Method 1. The criterion of corrosion resistance is the value of the saturation current density, which is established on the test sample after its exposure to the model environment at a potential of $\mathrm{E}=$ $300 \mathrm{mV}$ for 1 hour. As shown in paper [2], the results of tests according to this method correlate well with the actual corrosion rate under operating conditions of oilfield pipelines in Western Siberia and, accordingly, with the terms of their operation before the formation of through corrosion damage. When the saturation current density is less than $6.7 \mathrm{~mA} / \mathrm{cm}^{2}$, the corrosion rate under operating conditions is not more than $1.1 \mathrm{~mm} /$ year, and when the saturation current density is less than 6.2 $\mathrm{mA} / \mathrm{cm}^{2}$, it is not more than $0.3 \mathrm{~mm} /$ year. An increase in the saturation current density to $7.3-8.5 \mathrm{~mA} / \mathrm{cm}^{2}$ corresponds to an increase in the corrosion rate to 1.5 $2.2 \mathrm{~mm} /$ year.

In this paper, the corrosion resistance of steels was assessed in relation to marine conditions, based on the results of dynamic corrosion tests, which were carried out in a moving medium - a simulator of seawater in an installation that provided the flow movement along the surface of samples at a speed of about $1 \mathrm{~m} / \mathrm{s}$. An aqueous
$3 \%$ sodium chloride solution was used as a corrosive medium. The tests were carried out for 144 hours, the solution was replaced twice during the whole test period. According to the data on weight loss, working surface area, and duration of the test, the corrosion rate of the samples was calculated. This method is hereinafter conventionally called Method 2.

To identify the unfavorable components of the structure around which corrosion centers are formed, a method was used to identify the initial stage of corrosion. The essence of the method is a potentiostatic holding of a metallographic specimen at a given potential for $1 \mathrm{~min}$, starting from the potential of full immunity $(-700 \mathrm{mV})$ with subsequent displacement by $5 \ldots 10 \mathrm{mV}$ toward positive values to a potential at which the anode current begins to be recorded, which indicates the initiation of dissolution. Analysis of the sample surface on a scanning electron microscope equipped with an energy-dispersive analyzer allows identifying the structural elements around which the centers of local corrosion are formed.

\section{Results and discussion}

The results of corrosion tests of the studied steel of laboratory smelting according to Method 1 (saturation current density I, mA/ $\mathrm{cm}^{2}$ ) (from paper [4]) and Method 2 are shown in Table 2.

Table 2. The results of corrosion tests of the studied steel of laboratory smelting by various methods

\begin{tabular}{|c|c|c|}
\hline $\begin{array}{c}\text { Smelt } \\
\text { No. }\end{array}$ & $\begin{array}{c}\mathrm{i}, \mathrm{mA} / \mathrm{cm}^{2} \\
(\text { Method 1) }\end{array}$ & $\begin{array}{c}\text { Corrosion rate, } \\
\text { mm/year (Method 2) }\end{array}$ \\
\hline 1 & 4.90 & 0.96 \\
\hline 2 & 5.05 & 0.50 \\
\hline 3 & 5.75 & 0.68 \\
\hline 4 & 6.16 & 0.68 \\
\hline 5 & 5.82 & 0.73 \\
\hline 6 & 5.49 & 0.63 \\
\hline 7 & 5.58 & 0.78 \\
\hline 8 & 5.62 & 0.52 \\
\hline
\end{tabular}

As indicated in paper [4], steels 1, 2, and 6, in which the chromium content is at the upper limit, have the best corrosion resistance (low values of saturation current density). The aluminum content has the strongest effect on the corrosion resistance of steel under operating conditions of oilfield pipelines, with an increase in which the current density increases, that is, the corrosion resistance decreases (see Fig. 1a). With increase in chromium content, corrosion resistance increases. 


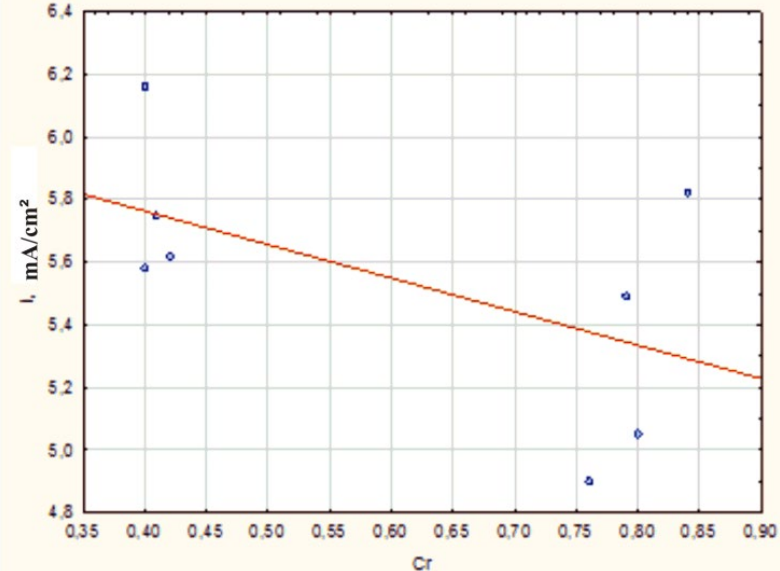

a)

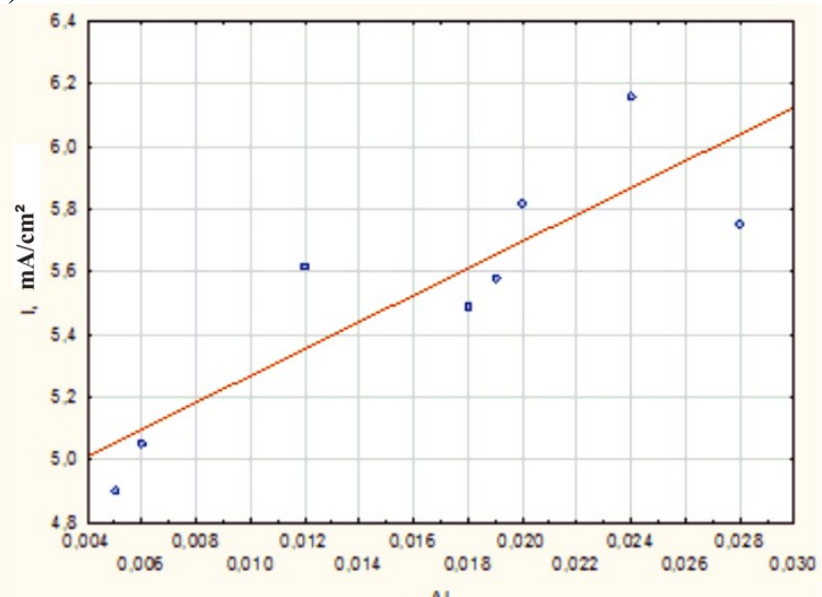

(b)

Fig. 1. Dependence of saturation current density on: a) aluminum content $(\mathrm{r}=0.86140), \mathrm{b})$ chromium content $(\mathrm{r}=$ 0.5492)

When tested according to Method 2, steels 2 and 8 with low carbon content demonstrated a higher corrosion resistance (a corrosion rate of about $0.5 \mathrm{~mm} / \mathrm{year}$ ). Their difference from other steels with low carbon content (4 and 6 ) is in the lower aluminum content. At the same time, steel 8 is distinguished by the lowest carbon content of all the steels studied, while steel 2 has high nickel content. That is, during the testing simulating marine conditions, characterized by a higher content of chlorine ions compared to oilfield media, as well as free access of oxygen, an increase in corrosion resistance results from a decrease in the content of carbon and aluminum in steel, as well as alloying with nickel.

When testing a sample of steel 4 with relatively high aluminum content by the method of detecting the initial stage of corrosion, it was found that local corrosion centers had formed around inclusions of corundum with a small amount of manganese sulfide particles released on them. This confirms that such inclusions show corrosive activity. It should be noted that such inclusions were formed in the steel of laboratory smelting, deoxidated with aluminum. In modern industrial steel, deoxidation products have a more complex composition, which can both reduce (calcium aluminates) and increase (modified inclusions of magnesium-aluminate) corrosion resistance of steel compared to that with corundum inclusions.

\section{Conclusions}

It has been established that part of the requirements for steels with increased corrosion resistance for oilfield pipelines and that for marine conditions are the same, but there are significant differences as well. The general requirement is to ensure the purity of unfavorable types of nonmetallic inclusions, the formation of nonmetallic inclusions of favorable morphology that modern technologies allow.

Increasing the carbon content does not lead to a decrease in the corrosion resistance of steel for oilfield pipelines, in the absence of micro-alloying elements in it. Unlike oilfield pipelines, in marine conditions, which are characterized by a higher content of chlorine ions as compared to oilfield media, as well as free oxygen access, a decrease in carbon content, as well as alloying with nickel, leads to an increase in the corrosion resistance of steel. It is advisable to develop requirements for steels, providing increased corrosion resistance in seawater to increase the terms of maintenance-free period, reduce metal consumption by reducing the corrosion allowance of steels used in shipbuilding.

\section{References}

1. I.G. Rodionova, A.I. Zaitsev, O.N. Baklanova, et al. Modern approaches to improving the corrosion resistance and operational reliability of steels for oilfield pipelines (Metallurgizdat, Moscow, 2012) [in Russian]

2. I.G. Rodionova, O.N. Baklanova, A.V. Amezhnov, A.V. Knyazev, A.I. Zaitsev, M.V. Feoktistova Steel 10 (2017) [in Russian]

3. A.V. Amezhnov, I.G. Rodionova, , A.I. Zaitsev, B.M. Mogutnov, O.N. Baklanova The problems of ferrous metallurgy and materials science, 3 (2018). [in Russian]

4. I.G. Rodionova, M.V. Feoktistova, O.N. Baklanova, A.V. Amezhnov, D.L. Dyakonov, The Metallurg, 9 (2017) [in Russian]

5. A.V. Amezhnov, I.G. Rodionova, A.I. Batsalev, et al., The Metallurg, 10 (2018) [in Russian]

6. I.G. Rodionova, A.I. Zaitsev, O.N. Baklanova, A.Yu. Kazankov, N.I. Endel, D.V. Kudashov, G.V. Semernin, S.E. Tsibrov, Patent 2554659 of the Russian Federation. (published June 15, 2015) 